\title{
EMERGÊNCIAS EM ADULTOS PORTADORES DE SÍNDROME DE IMUNODEFICIÊNCIA ADQUIRIDA
}

\author{
EMERGENCIES IN ADULTS WITH ACQUIRED IMMUNODEFICIENCY SYNDROME
}

José Fernando de Castro Figueiredo \& Alcyone Artioli Machado

Docentes. Divisão de Moléstias Infecciosas e Tropicais. Departamento de Clínica Médica. Faculdade de Medicina de Ribeirão Preto-USP. CorResPondência: Prof. Dr. José Fernando de Castro Figueiredo. Divisão de Moléstias Infecciosas e Tropicais. Departamento de Clínica Médica. Faculdade de Medicina de Ribeirão Preto da USP. Avenida Bandeiranres,3900. CEP 14049-900. Ribeirão Preto, SP, Brasil. E-mail: jfcfigue@fmrp.usp.br

FIGUEIREDO JFC \& MACHADO AA. Emergências em adultos portadores de síndrome de imunodeficiência adquirida. Medicina, Ribeirão Preto, 36: 357-364, abr./dez.2003.

RESUMO - Pacientes com aids são freqüentemente atendidos em serviços de emergências. Com o objetivo de sistematizar o atendimento de urgência a tais pacientes, são apresentadas, no presente trabalho, as normas gerais de conduta para a abordagem inicial do caso, bem como as complicações mais comuns, verificadas em nosso meio. São abordados ainda os processos infecciosos mais freqüentes, com ênfase na apresentação clínica, no diagnóstico laboratorial e no tratamento.

UNITERMOS - Síndrome de Imunodeficiência Adquirida. Tratamento de Emergência. Infecções Oportunistas.

\section{1- INTRODUÇÃO}

Com o evoluir da epidemia de aids, o atendimento de pacientes portadores dessa síndrome, em serviços de urgências, tem sido cada vez mais freqüente. A análise dos casos atendidos no HCFMRPUSP tem demonstrado que quase a totalidade dos pacientes em seguimento no hospital, em algum momento da evolução da doença, necessitam de cuidados de urgência. Além disso, em cerca da metade dos casos, suspeita-se do diagnóstico inicialmente, quando as primeiras complicações da imunodeficiência fazem com que os pacientes procurem atendimento médico na Unidade de Emergência do HCFMRP-USP.

A abordagem clínica dos pacientes com aids tem evoluído bastante nos últimos anos, o que tem resultado na maior sobrevida dos pacientes e na melhora sensível de sua qualidade de vida, o que se baseia em três premissas principais: 1 - o retardo na progressão e na melhora da imunodeficiência pelo uso adequado dos anti-retrovirais; 2 - a prevenção de infecções oportunistas 3 - o diagnóstico e tratamento precoce das complicações - processos infecciosos e doenças neoplásicas.

Com base nessas premissas, apresentamos, a seguir, as diretrizes gerais do atendimento de urgência de algumas complicações mais comuns nesses pacientes.

\section{2- DIAGNÓSTICO DE AIDS}

Deve-se suspeitar sempre que houver situações clínicas indicativas de uma deficiência imunológica grave, excluídas outras causas comuns de immunossupressão (uso de corticóides, neoplasias do tecido linfóide, etc). É habitual, nesses pacientes, o relato de situações capazes de sugerir o modo de contaminação, tais como a multiplicidade de parceiros sexuais, o uso de drogas injetáveis, antecedentes de transfusão de sangue ou derivados. É oportuno salientar que a simples menção dessas situações, na ausência de sin- 
tomas ou sinais indicativos de imunodeficiência não nos autoriza o diagnóstico presuntivo de aids, que deve sempre ser feito em bases clínicas. Uma vez havendo suspeita, o diagnóstico deve ser confirmado através da pesquisa de anticorpos anti-HIV, por método imunoenzimático (Elisa). A experiência tem demonstrado que, na presença de sinais e sintomas, um único resultado positivo do teste tem sido suficiente para a confirmação do diagnóstico. Devemos salientar ainda que, para o paciente e seus familiares, o diagnóstico de aids pode trazer consequiências importantes. Mais do que nunca, em tais casos, o médico, como líder da equipe de saúde, deve pautar sua conduta dentro dos mais rígidos padrões éticos, de forma a garantir o sigilo médico e o tratamento respeitoso do paciente. A revelação do diagnóstico deve ser feita ao paciente, o qual deve ser o responsável por transmitir o fato ao seu parceiro sexual. Caso o paciente não tenha informado ao seu contato sexual, o médico terá obrigação de informá-lo, pois há envolvimento de risco para terceiros.

\section{3- MANIFESTAÇÕES MAIS COMUNS E CONDUTA GERAL}

\section{1- Febre, adenomegalia, esplenomegalia}

A febre pode ser causada pela própria infecção pelo HIV, porém, quando alta e com duração de vários dias, faz supor a presença de processo infeccioso ou outra complicação. Se a causa da febre não é aparente ao exame clínico e laboratorial simples, colher amostras para hemocultura e encaminhar o paciente para o ambulatório especializado. Pacientes em estado grave devem ser hospitalizados e, se necessário, prescritos antimicrobianos. Hemocultura deve ser colhida para bactérias habituais, para fungos e para Mycobacterium.

Adenomegalia, além das causas habituais, pode estar relacionada com toxoplasmose, tuberculose, infecções fúngicas e linfomas, indicando a hemocultura, os exames sorológicos e a biópsia ganglionar. Essas complicações também levam à esplenomegalia, assim como às infecções piogênicas e virais, disseminadas. Hepatomegalia também pode ser encontrada.

\section{2- Manifestações gastrintestinais}

Sintomatologia do tubo digestivo proximal decorre comumente da candidíase, diagnosticada ao exame da orofaringe ou por exame endoscópico. Outras infecções e neoplasias são causa de vômitos, dor epi- gástrica e disfagia, sendo essencial a endoscopia para o diagnóstico e tratamento. Na hipótese de gastrite por medicamentos, deve-se verificar a possibilidade de suspendê-los temporariamente. A diarréia é freqüente nos doentes com aids, alguns apresentando cólicas abdominais, grande número de evacuações e perda líquida e eletrolítica suficiente para desidratálos, a ponto de requerer hidratação parenteral e reposição de potássio.

A icterícia, geralmente, relaciona-se com a hepatotoxicidade de medicações que os pacientes com aids podem estar recebendo, como a rifampicina, cuja administração deve ser interrompida, e os anti-retrovirais. A icterícia é também um sinal auxiliar no diagnóstico de septicemias e fungemias, motivando a solicitação de culturas para identificação do agente etiológico e antibioticoterapia. Tem sido observadas, também, hemorragia digestiva e complicações cirúrgicas (perfuração de víscera, etc), aplicando-se as condutas gerais para cada situação, associadas à investigação e ao controle de fatores relacionados à aids (plaquetopenia, uso de drogas mielotóxicas, neoplasias e infecções oportunistas intestinais).

\section{3- Manifestações respiratórias}

Tem maior importância as pneumonias bacterianas, a tuberculose e a pneumocistose, que serão comentadas adiante. Outras causas de pneumopatia são as infecções virais e fúngicas e a toxoplasmose, que se manifestam, principalmente, como infiltrado intersticial difuso. A comprovação das hipóteses diagnósticas é obtida com exames microbiológicos do escarro, hemocultura e testes sorológicos. Se o quadro clínico não permitir aguardar os resultados, o tratamento inicial para os doentes com infiltrado retículomicronodular pode ser feito com sulfametoxazoltrimetoprim (SMX-TMP), 800mg-160mg, a cada $8 \mathrm{~h}$. Aparentemente, as infecções pulmonares, em pacientes com aids, complicam-se mais vezes com pneumotórax e derrame pleural, exigindo drenagem cirúrgica.

A sinusite aguda também constitui uma urgência médica, sendo feito o tratamento com antimicrobianos (amoxicilina, amoxicilina/clavulanato, cefalexina, eritromicina) associados a descongestionante local e sistêmico.

\section{4- Manifestações neurológicas}

São indícios de comprometimento do sistema nervoso central a cefaléia persistente e até resistente a analgésicos, associada a febre e vômitos, alterações 
visuais, alterações da consciência e do comportamento, meningismo, crise convulsiva e sinais neurológicos focais. Os sinais de hipertensão intracraniana são mais freqüentes e exuberantes do que os sinais meníngeos, cuja ausência não exclui o diagnóstico de meningite. São manifestações de meningite (criptocócica, purulenta, tuberculosa), de massa expansiva intracerebral (granuloma toxoplásmico, fúngico, linfoma) ou de encefalite (herpesvírus, citomegalovírus, fungos, bactérias). O complexo aids-demência também ocasiona sintomalogia neuropsiquiátrica, contudo, devem ser excluídas as complicações infecciosas e neoplásicas antes de ser firmado tal diagnóstico. Com a melhora da sobrevida, têm sido vistos casos de leucoencefalopatia multifocal progressiva e de Doença de Chagas do sistema nervoso central, que podem se manifestar pelas alterações descritas acima. Em nosso meio, as manifestações mais comuns são devidas a toxoplasmose e a criptococose. O exame do líquido cefalorraqueano e a tomografia computadorizada do crânio são essenciais para a análise da etiologia e para o tratamento inicial.

\section{5- Manifestações dermatológicas}

$\mathrm{O}$ paciente com aids tem freqüentes reações de hipersensibilidade, relacionadas com medicações, picadas de insetos, etc. As manifestações variam desde um exantema pruriginoso até a síndrome de Stevens-Johnson. No caso de reação medicamentosa, suspende-se ou substitui-se a droga, iniciando com antihistamínico e, nos casos mais graves, utiliza-se a corticoterapia. Lesões disseminadas, do tipo papular, vesicular, papulopustulosas e ulcerações podem corresponder a disseminação hematogênica de infecções virais (herpes, varicela zoster), fúngicas (histoplasmose, paracoccidioidomicose) e bacterianas (septicemia, sífilis). Após a coleta de sangue para cultura, o doente deve ser encaminhado com urgência para esclarecimento diagnóstico (biópsia de pele, exames microbiológicos e sorológicos). O uso imediato de aciclovir ou outros antimicrobianos dependerá da impressão diagnóstica e da condição clínica e laboratorial do doente.

\section{6- Manifestações cardíacas}

A pericardite não é rara em pacientes com aids, tendo etiologia estafilocócica ou tuberculosa na maior parte dos casos e trazendo o risco de tamponamento cardíaco. O líquido pericárdico, quando drenado, deve ser enviado para análise citológica e microbiológica completa. É recomendável a utilização de uma droga anti-estafilocócica depois de colhidas amostras para hemocultura. Infecções virais, por Toxoplasma ou Trypanosoma podem ser causa de miocardite e insuficiência cardíaca. A endocardite ocorre, principalmente, nos pacientes que usam tóxicos por via endovenosa, aplicando-se a investigação usual para confirmação dessa suspeita clínica.

\section{7- Manifestações hematológicas}

Anemia intensa, ocasionada pelo próprio HIV, é observada em alguns casos, porém, comumente resulta da ação de drogas mielotóxicas, como a zidovudina (AZT) e o SMX-TMP. O tratamento de urgência consiste em transfusão de papa de hemácias, retirada das drogas tóxicas e, no caso do SMX - TMP, administração do ácido folínico. A plaquetopenia é complicação comum nos casos de aids, trazendo manifestações, como púrpura ou sangramento. Transfusão de papa de hemácias e de concentrado de plaquetas, além da retirada de qualquer medicação mielotóxica, são as medidas aplicáveis.

\section{8- Manifestações renais}

Retenção nitrogenada moderada e reversível, ocorre em doentes com maior grau de desidratação, em consequiência de transtornos gastrintestinais. Em casos esporádicos observa-se insuficiência renal, grave, para a qual se indicam a diálise e outras medidas usuais, próprias para a complicação.

As manifestações renais podem ser causadas por agentes infecciosos ou pelo uso de medicações como a anfotericina, gan- ciclovir, aciclovir e anti-retrovirais, como o indinavir, o qual pode levar a cálculos renais, se o paciente não fizer ingestão hídrica recomendada (3 1/dia).

\section{4- MANIFESTAÇÕES INFECCIOSAS}

Abordamos,a seguir, as patologias mais comuns em nosso meio

\section{1- Pneumonia por Pneumocystis carinii}

A pneumonia pelo $P$. carinii tem sido a complicação pulmonar mais comum nos pacientes com aids. Existem estimativas, que apontam que cerca de $75 \%$ dos pacientes acabam por apresentar essa complicação ao longo do tempo.

O sinais e sintomas da pneumocistose são usualmente aqueles de uma pnemonia difusa, de evolução aguda (poucos dias) ou insidiosa (2-4 semanas). 
Os pacientes se queixam de febre, tosse seca e dispnéia progressiva, que pode culminar com um quadro de insuficiência respiratória, com taquipnéia e cianose, mesmo em repouso. A radiografia de tórax freqüentemente revela infiltrado intersticial bilateral, com eventuais áreas de alveolização, principalmente em bases pulmonares, e a gasometria arterial, com freqüência, demonstra hipoxemia. Os achados clínicos e laboratoriais, acima enumerados, são suficientes para diagnóstico presuntivo de pneumocistose e, por si só, autorizam o início do tratamento. Frente à suspeita clínica, o diagnóstico etiológico deve ser sempre buscado através do exame do escarro e/ou do lavado bronco alveolar ou pela biópsia transbrônquica, corados pelo azul de toluidina ou prata/metenamina.

As principais drogas disponíveis, na atualidade, para o tratamento da pneumonia pelo $P$. carinii são a associação do sulfametoxazoltrimetoprim (SMX-TMP) e a Pentamidina, que apresentam eficácia semelhante, em torno de $75 \%-80 \%$ de cura no primeiro episódio da pneumonia. Em virtude do menor custo, da disponibilidade mais fácil e por apresentar menos efeitos colaterais, a droga de $1^{\text {a }}$ escolha é o SMZ-TMP, na dose de 75-100 mg/kg/d (do SMX), por via EV, em doses divididas, a cada $6 / 8 \mathrm{~h}$, durante 2 a 3 semanas. Os efeitos colaterais mais freqüentes são reações de hipersensibilidade e a toxicidade hematológica, com granulocitopenia e trombocitopenia. Essas últimas exigem controle freqüente pelo hemograma.

No caso de insucesso terapêutico ou aparecimento de intolerância às drogas, indica-se a Pentamidina, $4 \mathrm{mg} / \mathrm{kg} / \mathrm{dia}$ em infusão endovenosa lenta, durante 2 a 3 semanas. Os efeitos colaterais mais freqüentes dessa droga são hipotensão arterial, rash cutâneo, neutropenia, náuseas, vômitos e hipoglicemia. Constituem, ainda, alternativa para as drogas supracitadas, para os casos de intolerância ou insucesso terapêutico, a clindamicina, $900 \mathrm{mg}$ EV a cada $8 \mathrm{~h} \mathrm{du}-$ rante 10 dias, associada a Primaquina, $30 \mathrm{mg} / \mathrm{dia}$ durante 21 dias. Estudos controlados em pacientes com pneumonia grave $\left(\mathrm{PO}_{2}<60 \mathrm{mmHg}\right)$, têm indicado que o uso precoce de corticosteróides pode resultar em melhora mais rápida da função pulmonar. Nesses casos, pode-se empregar hidrocortisona $300 \mathrm{mg}$ EV a cada $6 \mathrm{~h}$, durante 3 a 4 dias consecutivos e a oxigenoterapia e/ou assistência ventilatória são indicadas.

\section{Profilaxia}

Há duas situações em que está formalmente indicada a profilaxia da pneumonia por P. carinii.
Numa primeira situação, indica-se a profilaxia para aqueles pacientes sob risco de desenvolverem a doença, usualmente, quando já apresentam sinais de imunodeficiência ou estão na iminência de apresentá-la. Nesse sentido, há estudos que demonstram que o risco de pneumonia por $P$ carinii passa a ocorrer quando a contagem de linfócitos $\mathrm{CD}_{4}{ }^{+}$cai abaixo de 200cél./ $\mathrm{mm}^{3}$. È a profilaxia chamada primária.

Uma outra situação diz respeito aos pacientes que já apresentaram um episódio de pneumocistose e busca-se evitar as recidivas, que são freqüentes. Trata-se, nesse caso, de profilaxia secundária. Em ambos os casos, usa-se SMX-TMP (800mg-160mg), a cada $12 \mathrm{~h}$, por tempo indefinido, ou, Pentamidina, 4 $\mathrm{mg} / \mathrm{kg}$ por via endovenosa, a cada 30 dias; ou, Pentamidina, $300 \mathrm{mg}$ em aerosol a cada 30 dias; ou, dapsona, $100 \mathrm{mg} \mathrm{VO/dia} \mathrm{por} \mathrm{tempo} \mathrm{indefinido.} \mathrm{Também,} \mathrm{nesse}$ caso, damos preferência ao uso do SMX-TMP. Com a utilização dos anti-retrovirais, ocorrendo a elevação e a estabilização do número de linfócitos $\mathrm{CD}_{4}{ }^{+}(\geq 200$ cél. $/ \mathrm{mm}^{3}$ ), a profilaxia pode ser suspensa.

\section{2- Tuberculose pulmonar e extrapulmonar}

Ao contrário das pneumonias bacterianas, cujo início é abrupto, quase sempre em 1 ou 2 dias, a tuberculose apresenta-se, usualmente, de maneira insidiosa. Os pacientes com tuberculose pulmonar freqüentemente apresentam tosse, escarro produtivo, hemoptise, dor pleurítica e dispnéia. Sintomas constitucionais como febre, fadiga, anorexia, perda de peso e suores noturnos são comuns. Sinais e sintomas de acometimento extrapulmonar (adenomegalia, hepatoesplenomegalia e anormalidades neurológicas) são freqüentes. Muito embora a tuberculose possa ocorrer concomitantemente com outras complicações infecciosas, na aids, com frequiência, as precede em meses ou anos, uma vez que o $M$. tuberculosis costuma ser mais virulento que os outros microrganismos oportunistas causadores de infecção na aids.

A tuberculose pulmonar, em pacientes com aids, manifesta-se radiologicamente, de forma atípica. Os infiltrados em ápice, cavitários, são incomuns. São freqüentes as adenomegalias hilares e mediastinais, os infiltrados alveolares difusos, lineares ou miliares, as localizações "atípicas" em lobos inferiores. Há, inclusive, casos descritos de culturas de escarro, positivas para o M. tuberculosis, em pacientes com raios$\mathrm{X}$ de tórax normal. Dessa forma, deve haver um alto grau de suspeita de tuberculose em todo o paciente com aids que apresente queixas indicativas de aco- 
metimento pulmonar e/ou febre prolongada e, no caso, adotar as medidas diagnósticas cabíveis. No caso do acometimento pulmonar, o exame do escarro corado pelo Ziehl Neelsen e a cultura em meio de LowensteinJensen são os métodos de escolha. A negatividade repetida dos exames ou a incapacidade do paciente em proporcionar um escarro adequado podem justificar a colheita do material obtido por lavagem broncoalveolar. Quando há acometimento extrapulmonar, podem estar indicadas, de acordo com o caso, a colheita de material ganglionar, líquor, aspirado de medula óssea, líquido pleural e sangue.

\section{Tratamento}

O tratamento da tuberculose deve ser iniciado, preferencialmente, após a comprovação etiológica (baciloscopia positiva). As provas terapêuticas somente são justificadas em situações especiais de gravidade do caso ou após tentativas infrutíferas de confirmação diagnóstica em pacientes com quadro clínico fortemente suspeito. O tratamento para adultos consiste na administração de Isoniazida, $400 \mathrm{mg} / \mathrm{d} \mathrm{em}$ dose única, em jejum, (300 mg em indivíduos com menos de $45 \mathrm{~kg}$ ); Rifampicina, $600 \mathrm{mg} / \mathrm{d}$ em dose única, em jejum (450 mg para indivíduos com menos de $45 \mathrm{~kg}$ ) e Pirazinamida, $20-30 \mathrm{mg} / \mathrm{kg} / \mathrm{d}$, em dose única diária. A Pirazinamida é administrada durante os 2 primeiros meses e, então, suspensa. A associação de Izoniazida e Rifampicina deve ser mantida por 6 meses. Durante o período de uso da Isoniazida, é recomendável a administração conjunta de piridoxina (Adermina ${ }^{\mathrm{R}}$ ), $40 \mathrm{mg}$ VO, 2 vezes ao dia, com o objetivo de minimizar a ocorrência de polineurite. Os efeitos colaterais mais comuns dos tuberculostáticos acima enumerados são náuseas, vômitos, epigastralgia e hepatotoxicidade e se tornam aparentes nos primeiros dias de tratamento. Para o controle da toxicidade das drogas recomendam-se, portanto, dosagens séricas de transaminases e bilirrubinas.

Estudos recentes sugerem que o tratamento isolado da tuberculose, em pacientes coinfectados com o HIV, que não estão em uso de anti-retrovirais, reduz, por si só, a carga viral plasmática. Assim, considerando-se que a terapia anti-retroviral não é uma emergência médica, sugere-se aguardar a estabilização do quadro clínico. Idealmente, procede-se a uma avaliação da contagem das células $\mathrm{CD}_{4}^{+}$e a quantificação da viremia após 30 a 60 dias do início da terapia antituberculosa, utilizando-se, então, esses parâmetros para indicar a terapia anti-retroviral.
Para a escolha do esquema anti-retroviral, devese também avaliar o risco de intolerância, de toxicidade e a capacidade de adesão do paciente ao tratamento, considerando-se a possibilidade de utilizar esquemas menos complexos ou mesmo postergar seu início naqueles com imunodeficiência menos grave. Entretanto, em pacientes com sinais (principalmente clínicos) de imunodeficiência mais grave, deve-se considerar o uso mais precoce da terapia anti-retroviral, devido ao risco elevado de morte nesses casos. Por outro lado, pacientes com contagem de células $\mathrm{CD}_{4}^{+}$ $>350$ cél. $/ \mathrm{mm}^{3}$ não devem iniciar terapia anti-retroviral na vigência de doença tuberculosa. Entretanto, sugere-se, para melhor definição da conduta, uma reavaliação clinicoimunológica após 30-60 dias do início do tratamento da tuberculose.

É importante considerar que a adesão adequada a ambos os esquemas, antituberculose e anti-retroviral, tomados de forma concomitante, é um grande desafio para o paciente, devido à elevada quantidade de comprimidos/cápsulas a serem ingeridos ao dia e à ocorrência de efeitos colaterais, particularmente nas primeiras semanas do tratamento. Portanto, deve-se considerar, sempre que possível, o adiamento do início do tratamento anti-retroviral em pacientes com coinfecção HIV/tuberculose, particularmente naqueles que apresentem quadros de imunodeficiência menos graves do ponto de vista clinicolaboratorial. A indicação de início da terapia anti-retroviral, em pacientes com coinfecção HIV/tuberculose, deve seguir os mesmos parâmetros clínicos e imunovirológicos, estabelecidos para pacientes soropositivos para o HIV, sem tuberculose em atividade.

\section{3- Pneumonias bacterianas}

Os pacientes portadores de aids são também mais susceptíveis a desenvolverem infecções por microrganismos encapsulados, notadamente S. pneumoniae e Haemophilus influenzae, agentes freqüentemente responsáveis por quadros de pneumonias adquiridas na comunidade. Ao contrário da pneumonia por P.carinii, as pneumonias bacterianas costumam ter um curso mais agudo, com poucos dias de febre alta e tosse produtiva. Os achados físicos de consolidação pulmonar, associados à leucocitose, neutrofilia e infiltrados focais ao Raio-X de tórax são indícios importantes de etiologia bacteriana. Os pacientes também estão sob maior risco de apresentarem disseminação hematogênica do processo e, dessa maneira, o tratamento deve ser iniciado o mais 
precocemente possível, após colheita de hemoculturas e cultura do escarro.

Uma causa comum de pneumonia bacteriana hematogênica em nosso meio é o $S$. aureus, principalmente em pacientes usuários de drogas ilícitas injetáveis. Nesses casos, infiltrados pulmonares focais podem representar o primeiro indício de embolização séptica para os pulmões, a partir de vegetações em válvula tricúspide.

Levando-se em conta a condição clínica do paciente, a extensão do acometimento pulmonar e os agentes etiológicos mais prováveis, os quadros de menor gravidade podem ser tratados em regime ambulatorial. Para tanto, indica-se Amoxicilina $500 \mathrm{mg}$ VO a cada $8 \mathrm{~h}$ ou Amoxicilina/clavulanato $500 \mathrm{mg}$ VO a cada 8 h. Para os casos mais graves, recomenda-se o uso de Amoxicilina/clavulanato na dose de $1 \mathrm{~g}$ EV a cada $8 \mathrm{~h}$.

\section{4- Neurotoxoplasmose}

Muito embora os portadores de aids possam adquirir a infecção aguda pelo Toxoplasma gondii através da ingestão de oocistos ou cistos do parasita, a grande maioria das infecções clinicamente aparentes no paciente com aids são resultado da reativação de focos latentes do Toxoplasma gondii, adquiridos em época anterior à imunossupressão. Apesar de que, nessas circunstâncias, possa haver cistos latentes em diversos locais (SNC, retina, musculatura estriada, coração, pulmões, gânglios linfáticos, etc.), a reativação no sistema nervoso central é, de longe, a mais comum e a mais grave. Apresenta-se, via de regra, como manifestação de encefalite, abscesso cerebral e lesões expansivas, de maneira isolada ou associada. O quadro clínico vai depender, portanto, do grau de resposta inflamatória ao cisto reativado, $\mathrm{da}(\mathrm{s}) \operatorname{sua}(\mathrm{s})$ localização(es) e do efeito de massa produzido. São comuns a presença de febre, cefaléia, crises convulsivas, alterações de consciência e sinais focais ao exame neurológico.

A comprovação do diagnóstico é difícil em virtude de que os métodos não invasivos não são confirmatórios. O exame do líquor pode ser normal (no caso de lesões intraparenquimatosas) ou mostrar-se compatível com o quadro de meningoencefalite (celularidade baixa, com predomínio de linfócitos e hiperproteinorraquia). A tomografia computadorizada do crânio revela, principalmente, áreas hipodensas, únicas ou múltiplas, rodeadas por halo de reforço após a administração de contraste, que se localiza mais comu- mente nos gânglios da base e na junção corticomedular e são circundadas por áreas de edema, criando efeito de massa. A ressonância magnética, geralmente, apresenta mesmas alterações, sendo mais sensível, mostrando, por vezes, maior número de lesões.

A pesquisa de anticorpos anti-Toxoplasma no soro e no LCR é positiva na maioria dos casos, às custas de $\lg G$, traduzindo infecção pregressa. A ocorrência de exame sorológico negativo é um dado importante contra essa hipótese diagnóstica, porém não a afasta. Baseado nos dados acima, na maioria dos casos, o diagnóstico é presuntivo e poderá vir a ser reforçado pela melhora do paciente após o tratamento específico.

A terapêutica ideal continua sendo o uso combinado de Sulfadiazina 1,0 g VO de 6/6 hs, Pirimetamina $75-100 \mathrm{mg} / \mathrm{d}$ no $1^{\circ}$ dia e a seguir $25-50 \mathrm{mg} / \mathrm{d}$, e ácido folínico $10 \mathrm{mg} \mathrm{VO} / \mathrm{d}$, para amenizar os efeitos supressivos das drogas sobre a medula óssea. Esse esquema deverá ser mantido por 3 a 4 semanas, após o que a dose será reduzida à metade e mantida a longo prazo, para reduzir o risco de recidivas. A alternativa terapêutica para os pacientes alérgicos às sulfas consiste na associação de Clindamicina 900-1200 mg VO de $6 / 6$ h, Pirimetamina $75-100 \mathrm{mg} / \mathrm{d}$ no $1^{\circ}$ dia e, a seguir, $25-50 \mathrm{mg} / \mathrm{d}$ e ácido folínico $10 \mathrm{mg} / \mathrm{VO} / \mathrm{d}$. Com o tratamento anti-retroviral, caso haja elevação e manutenção do número de linfócitos $\mathrm{CD}_{4}^{+}>200$ cél. $/ \mathrm{mm}^{3}$, a terapêutica de manutenção poderá ser suspensa.

\section{5- Neurocriptococose}

A meningoencefalite pelo Criptococcus neoformans tem sido bastante comum em pacientes com aids e, freqüentemente, pode ser a primeira manifestação da doença, não raramente acompanhada por fungemia. A disseminação hematogênica do Criptococcus neoformans resulta no acometimento de vários órgãos e sistemas, mas o tropismo do fungo pelo SNC e meninges é característico. O acometimento neurológico tem sido a apresentação inicial em cerca de $80 \%$ a $90 \%$ dos casos e os sinais e sintomas mais comuns são a febre, cefaléia, náuseas, vômitos, alterações do estado de consciência, convulsões e sinais de irritação meníngea. Sinais neurológicos focais são menos comuns, ao contrário do verificado na neurotoxoplasmose, principal entidade a ser considerada no diagnóstico diferencial.

O exame do líquor revela, na maioria dos casos, numerosos fungos encapsulados, com brotamentos, facilmente identificados em preparações com Tinta 
da China. A resposta celular é pobre, com poucos linfócitos, hipoglicorraquia moderada e hiperproteinorraquia. A confirmação do diagnóstico pode ser feita pela detecção de antígenos no líquor (aglutinação do látex) e pelo isolamento do fungo a partir do líquor e do sangue.

A tomografia computadorizada do crânio é freqüentemente normal, evidenciando, ocasionalmente, edema cerebral e sinais de hidrocefalia. Lesões focais expansivas são incomuns.

A terapêutica convencional, utilizando a Anfotericina B, deve ser administrada de forma usual. Inicia-se administrando $5 \mathrm{mg}$ da droga por dia, diluídas em $500 \mathrm{ml}$ de SG5\% em infusão venosa gota a gota, durante $6 \mathrm{~h}$. Recomenda-se, ainda, adicionar à prescrição, $500 \mathrm{ml}$ de $\mathrm{SG} 5 \%$ contendo $1,0 \mathrm{ml}$ de metilpirazolona e $1.250 \mathrm{U}$ de heparina, correndo em $\mathrm{Y}$ com o soro anterior, em $8 \mathrm{~h}$. A partir do $2^{\circ}$ dia, aumenta-se a dose da Anfotericina B de 5 em $5 \mathrm{mg}$ por dia, até atingirmos uma dose diária de manutenção em torno de $0,8 \mathrm{mg} / \mathrm{kg} / \mathrm{dia}$, não excedendo $50 \mathrm{mg} / \mathrm{kg} / \mathrm{dia}$, dose que deverá ser mantida até o final do tratamento, quando se atingir uma dose total acumulada maior que 2,0 $\mathrm{g}$ do medicamento. Salientamos, no entanto, que a decisão de suspender o tratamento deve estar baseada na cura clínica e micológica. Exige-se, portanto, que as culturas para Cryptococcus estejam negativas nessa etapa. Os efeitos colaterais mais comuns da Anfotericina B são náuseas, vômitos, febre e tremores, geralmente durante a infusão, que tendem a melhorar com a continuidade do tratamento. Mais tardiamente, aparecem, com frequiência, sinais de toxicidade renal, com aumento da creatinina e queda dos valores do potássio sérico (que pode exigir reposição). Recomenda-se portanto, na vigência do tratamento, acompanhar de perto os valores de creatinina e eletrólitos no soro. Esses efeitos são facilmente contornáveis, porém, em casos especiais de intolerância, podemos optar por formulações lipídicas da anfotericina-B, melhor toleradas mas muito mais onerosas.

Apesar de muitos pacientes apresentarem cura clínica com o tratamento, a erradicação completa do fungo parece improvável. As recaídas são freqüentes e passam a exigir tratamento profilático a longo prazo. Os esquemas recomendados para esse fim incluem o uso de Fluconazol $400 \mathrm{mg} \mathrm{VO/d,} \mathrm{ou,} \mathrm{alternativamente,}$ $1 \mathrm{mg} / \mathrm{kg}$ de Anfotericina B por via EV 1 vez/semana.

\section{6- Candidíase de orofaringe}

É a infecção oportunista mais comum e, apesar da pouca gravidade, necessita de tratamento adequado. Nos casos leves, consegue-se o seu controle com tratamento local. Recomenda-se, nessa fase, lavagem e remoção das placas com água bicarbonatada e a aplicação tópica de Nistatina. Nos casos mais graves, o controle só é conseguido através de antifúngicos sistêmicos. Utiliza-se então Fluconazol, 200 mg VO $1 \mathrm{vez} / \mathrm{dia}$.

\section{7- Candidíase de esôfago}

Complicação bastante comum, manifesta-se por náuseas, vômitos, sialorréia, odinofagia e dor epigástrica ou retroesternal. Deve ser tratada por via sistêmica com Fluconazol, 200-400 mg/dia em dose única, por 1-6 dias. Após a cura clínica é necessário o tratamento local supressivo com nistatina VO, para reduzir as recidivas.

\section{8- Diarréia}

É também bastante comum e contribui para a piora do estado geral e nutricional do paciente. Dependendo da gravidade do quadro, pode exigir reposição hídrica e eletrolítica. A busca da etiologia do processo é fundamental para o tratamento adequado e devem ser solicitados, nessas circunstâncias, coprocultura, pesquisa de Isospora belli e Criptosporidium $s p$ nas fezes, pesquisa de cistos de Giardia lamblia e larvas de Strongyloides stercoralis.

As bactérias mais comumente responsáveis por quadro diarréico nos pacientes com aids, no nosso meio, são Shigella e Salmonella e podem ser tratadas com Norfloxacina $400 \mathrm{mg}$ VO de $12 / 12 \mathrm{~h}$, por 10 dias. O controle da Isosporíase pode ser conseguido pelo emprego de SMX-TMP (800mg-160 mg) 2 vezes/dia, durante 3-4 semanas. Recomenda-se para o tratamento da criptosporidíase, Espiramicina, 1,0 g VO de 6/6 $\mathrm{h}$, por tempo indefinido, com resultados inconstantes. Alguns pacientes com criptosporidíase parecem se beneficiar do uso combinado de antidiarréicos, como por exemplo, a Loperamida, na dose de 1 comprimido VO de $8 / 8$ ou $6 / 6 \mathrm{~h}$.

Indica-se o uso de Metronidazol, $250 \mathrm{mg}$ VO de $12 / 12 \mathrm{~h}$ durante 5 dias para o tratamento da giardíase e o Thiabendazol, $25 \mathrm{mg} / \mathrm{kg}$ em duas tomadas diárias, durante 10 dias para a estrongiloidíase.

Havendo necessidade de se iniciar tratamento com antimicrobianos antes de obtidos os resultados dos exames de fezes, recomenda-se o uso de SMXTMP (800 -mg/l60 mg) de 12 em 12 h, VO. 
FIGUEIREDO JFC \& MACHADO AA. Emergencies in adults with acquired immunodeficiency syndrome. Medicina, Ribeirão Preto, 36: 357-364, apr./dec.2003.

ABSTRACT- Patients with AIDS are frequently treated in emergency units. In order to sistematize emergency treatment for these patients, general rules for the initial approach to each case and for the management of the most common complications observed in our population are presented here. The most frequent infectious processes are also discussed, with emphasis on clinical presentation, laboratory diagnosis and treatment.

UNITERMS - Acquired Immunodeficiency Syndrome. Emergency Treatment. Opportunistic Infections.

\section{REFERÊNCIAS BIBLIOGRÁFICAS}

1 - BRASIL. MINISTÉRIO DA SAÚDE. BOLETIM EPIDEMIOLÓGICO. Disponível em http://www.aids.gov.br

2 - BOLLELA VR \& MACHADO AA. Terapêutica anti-retroviral. MEDICINA, Ribeirão Preto 29: 449-459, 1996.

3 - COSTA JC; GIR E; MACHADO AA; SANTIS GC; DUARTE G; MARTINEZ R; MORIYA TM \& FIGUEIREDO JFC. Análise da necessidade de repetição de teste diagnóstico sorológico da infecção pelo HIV-1 em indivíduos com comportamento de risco. MEDICINA, Ribeirão Preto 25: 315-319, 1992.

4 - FIGUEIREDO JFC; REIS VMF; MACHADO AA; OYAMA SR; MARTINEZ R; FIGUEIREDO LTM; FONSECA BAL; COSTA JC; MOYA MJ \& CASTRO G. Características clínicas e epidemiológicas de pacientes da região de Ribeirão Preto, SP, Brasil, com AIDS e infecções oportunistas. MEDICINA, Ribeirão Preto 33: 141-146, 2000.
5 - MACHADO AA; FIGUEIREDO JFC; GOULART APEG; PALAVÉRI V \& MARTINEZ R. Perfil clínico-epidemiológico de pacientes de Ribeirão Preto, São Paulo, Brasil com AIDS e infecções oportunistas. MEDICINA, Ribeirão Preto 30: 106-112, 1997.

6 - TALAN DA \& KENNEDY CA. The management of HIV-related illness in the emergency department. Ann Emerg Med 20:1355-1365, 1991.

7 - WHITE D \& GOLD JWM. Medical management of AIDS patients. Med Clin North Am 76:1-287, 1992. 